\title{
Successful deliveries of uterine prolapse in two primigravid women after obstetric management and perinatal care: case reports and literature review
}

\author{
Kana Wang ${ }^{1,2}$, Jian Zhang ${ }^{3}$, Tingting Xu ${ }^{1,2}$, Haiyan Yu ${ }^{1,2}$ Xiaodong Wang ${ }^{1,2}$ \\ ${ }^{1}$ Department of Obstetrics and Gynecology, West China Second University Hospital, Sichuan University, Chengdu, China; ${ }^{2}$ Key Laboratory of Birth \\ Defects and Related Diseases of Women and Children (Sichuan University), Ministry of Education, Chengdu, China; ${ }^{3}$ Sichuan Academy of Medical \\ Sciences \& Sichuan Provincial People's Hospital, Chengdu, China \\ Correspondence to: Haiyan Yu; Xiaodong Wang. No. 20, 3rd section, South Renmin Road, Chengdu 610041, China. Email: fanjy422@163.com; \\ wangxd_scu@sina.com.
}

\begin{abstract}
Uterine prolapse as a common form of pelvic organ prolapse (POP) is very rare during pregnancy. The literature was extremely limited concerning the management and causation of uterine prolapse during pregnancy women, especially in nulliparous women. We reported two cases of uterine prolapse in two primigravid female. Analysis and recommendations regarding the reasons and management of this condition was provided with past 20-year literature review. In our report, two patients noticed a lump protruding from vagina in the third and second trimester of pregnancy and were found uterine prolapse ( $28+3$ weeks and 24 weeks of gestation respectively). One patient' prolapsed uterus cannot be returned spontaneously, vaginal packing with sterilized oil gauze and indwelling catheter were executed. She was hospitalized and with careful antenatal care. Corticosteroids were administered for fetal lung maturation. But the patient underwent emergency cesarean section because of obstetric factors two days later and two healthy twins were born. Another one treated with conservative antenatal management for a month, and with cesarean delivery at 33+6 weeks of pregnancy. After the delivery, patients were found no uterine prolapse at one-month post-partum examination. Successful pregnancy outcome of uterine prolapse depending on symptomatology, severity of the prolapse, obstructed status and the preference of patients; based on these facts require individualized management and treatment.
\end{abstract}

Keywords: Uterine prolapse; pregnancy; primigravid women; case report

Submitted Jun 27, 2020. Accepted for publication Oct 22, 2020.

doi: 10.21037/apm-20-1322

View this article at: http://dx.doi.org/10.21037/apm-20-1322

\section{Introduction}

Uterine prolapse as a form of pelvic organ prolapse (POP) is extremely rare complicating pregnancy, which can be occurred in the course of pregnancy or in the prenatal and postnatal women. Complications resulting from prolapse of the uterus during pregnancy including cervical infection, spontaneous abortion and preterm labor, fetal demise as well as acute urinary retention and urinary tract infection that can cause maternal sepsis and death (1). Moreover, affected women may be at particular risk of dystocia during labor that could necessitate emergency intervention for delivery (2). To date, the literature was very limited concerning the management of prolapse during pregnancy in young women. In the present report, we described two cases of uterine prolapse in two young primigravid female who were treated by the returns of prolapsed uterine from vagina, and resulting in successful cesarean deliveries. In addition, we performed a reviewing for English-language literature for the similar cases in the past 20 years, which were summarized in the current 

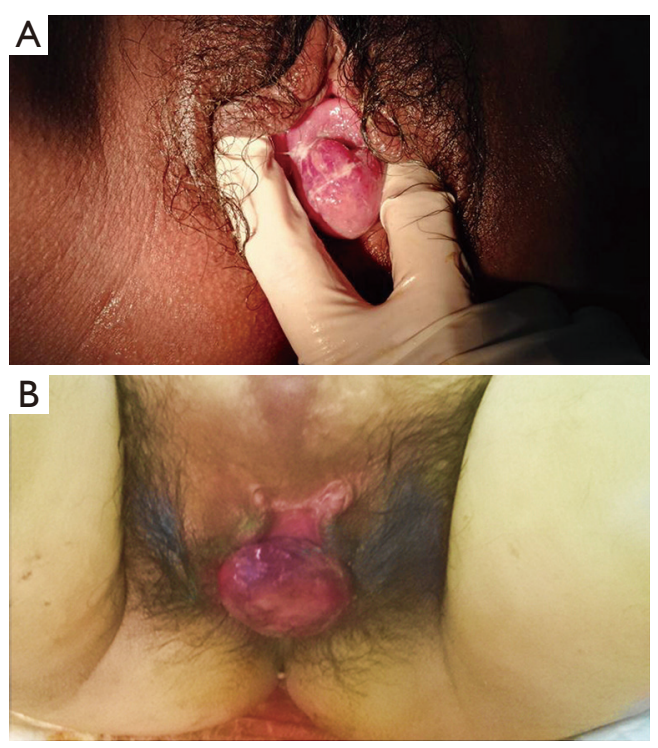

Figure 1 Clinical examination revealed uterine prolapse in two cases. (A) Physical exams show second-degree uterine prolapse in case 1, the elongated and edematous uterine cervix outside of vaginal introitus. (B) Physical exams show second-degree uterine prolapse in case 2.

study. We present the following article in accordance with the CARE reporting checklist (available at http://dx.doi. org/10.21037/apm-20-1322).

\section{Case presentation}

Two cases were hospitalized in West China Second University Hospital. All procedures performed in studies involving human participants were in accordance with the ethical standards of the institutional and/or national research committee(s) and with the Helsinki Declaration (as revised in 2013). Written informed consent was obtained from the patient.

\section{Case 1}

A 29 -year-old woman, gravida 1 para 0 , was admitted in her $28+3$ weeks of twin gestation for the complaints of labor pain and uterine prolapse in pregnancy. She had no history of uterine prolapse prior to the current pregnancy. This pregnancy with assisted reproductive technology by in vitro fertilization embryo transfer (IVF-ET). In the firsttrimester, ultrasound examination revealed double chorionic twin pregnancy. At 21+3 weeks of pregnancy, she was found suffering from intrahepatic cholestasis of pregnancy (ICP), which treated by ursodeoxycholic acid capsules $(250 \mathrm{mg}$, bid for 2 months) in outpatient department. She presented to emergency department of our hospital at $28+3$ weeks of gestation because of a uterine prolapsed and felt pain in the lower abdomen. Upon admission, clinical examination revealed uterine prolapse at POP-Q (pelvic organ prolapse quantitative examination) stage II. The cervix appeared edematous, ulcerated with transparent secretion and the sexternal cervical orifice was closed (Figure 1). The two fetuses with normal amniotic fluid and positive fetal heart rates and no fetal abnormality were identified. But the ultrasound examination revealed a cystic occupying site about $9.3 \times 2.0 \times 6.9 \mathrm{~cm}^{3}$ in front of uterus. Non-stress test was reactive and there was no contraction. The patient was immediately hospitalized. Routine laboratory tests, vaginal secretions and urine cultures were obtained; prophylactic broad-spectrum antibiotic therapy was initiated (cefmetazole sodium for injection, $1 \mathrm{~g}, \mathrm{q} 12 \mathrm{~h}$ ). Corticosteroids were administered for fetal lung maturation $(6 \mathrm{mg}$, bid, intramuscular injection for two days). Two days later, in her $28+6$ week of gestation, the patient underwent an emergent cesarean section for the indication of fetal distress and intraperitoneal bleeding. Two male neonates of 1,410 and 1,130 g with Apgar score 9-10-10 and 8-9-10 necessitating pediatric care were delivered. During operation, a mass consisting of the omentum, intestine and the left wall of the uterus was been found at left adnexal area, and been treated accordingly. After the delivery, the uterine prolapse promptly improved spontaneously. There was no uterine prolapse at her one-month post-partum examination.

\section{Case 2}

A 26-year-old woman, gravida 1 para 0 , was referred to the obstetric emergency unit at the $33+4$ weeks of gestation complaining of uterine prolapsed and vaginal bleeding after defecated. She had no history of uterine prolapse prior to the current pregnancy but had the trauma history of lower abdominal wall in her childhood. She first noticed a lump protruding from her vaginal at 24 weeks, which she was able to reduce manually. She attended the regular antenatal examination, and was found with Mediterranean anemia and gestational diabetes. Ultrasound revealed that placenta completely covered the cervix. A complete rest at home and with intensive clinics were recommended, but the patient stick to work for a month. At $33+4$ weeks of pregnancy, the patient presented with uterine prolapsed which can't return manually and accompany with vaginal 
bleeding. When she reached emergency department, the amount of bleeding was about $120 \mathrm{~mL}$. After admission, emergency urinary retention was performed and the acute tocolysis drugs (magnesium sulfate, pump in $2 \mathrm{~g}$ per hour) were used to inhibit contractions. In the operation, the prolapsed cervix was been found elongated and edematous, the uterine prolapse was been judged at POP-Q stage II; the cervical orifice was closed and no obvious bleeding (Figure 1). Vaginal packing with sterilized oil gauze and indwelling catheter were executed. Corticosteroids were administered for fetal lung maturation $(6 \mathrm{mg}$, bid, intramuscular injection for two days). Two days later, the patient consented to a cesarean section. A female infant weighing 2,260 g with Apgar score 10-10-10 was safely delivered. After 1 month, she had no longer uterine prolapse. The patient's post puerperal examination on control 6 months after the operation revealed complete regression of uterine prolapse.

\section{Discussion}

Uterine prolapsed as a kind of gynecologic condition of POP, that is normally present in the postmenopausal women when the pelvic floor disordered. The literature is quite poor concerning the uterine prolapse associated in young women. It is well-known that the major risk factors for POP related to pelvic floor disorder, advanced age, family history of uterine prolapse, and pelvic trauma history (3). Multiparity as acquired factors may lead to maternal connective tissue disorder. Uterine prolapse during pregnancy primarily occurs in multiparous women, especially in that women with vaginal instrumental delivery, young age at first delivery, previous prolonged second stage of labor, and previous neonatal birthweight (1). The weaknesses in the pelvic floor such as collagen defects, abnormal pelvic structure were uncommon congenital predisposing factors of uterine prolapse, and therefore occurred in a nulliparous woman is extremely rare (2). In the current study, we reported two case of uterine prolapse in nulliparous patient, and reviewed the literature for past 20 years, just found four cases in nulliparous woman since 1997 (Table 1) (1,4-24).

In our first case, the patient with twin gestation and a large cystic occupying of pelvic cavity resulting in increased intra-abdominal pressure, probably was the main cause for the uterine prolapse. But in the second case, none of congenital or acquired risk factors was present. The patient was been found with Mediterranean anemia and gestational diabetes. Therefore, we speculated that the nutritional status in pregnant women maybe the potential factors for uterine prolapse, which to some extent led to tissue edema, tissue elasticity decreased, and gradually associated to connective tissue disorder. Ishida et al. reported a case of uterine prolapse in a nulliparous woman during late gestation, and the woman also did not have any of the known risk factors for uterine prolapse (22). They suggested that uterine prolapses in pregnant women may result from physiological increases in cortisol and progesterone levels, which lead to a concomitant softening and stretching of the pelvic tissues. The connective tissue composition abnormalities are suspected to contribute to the development of POP, particularly since the connective tissue associated with the urogenital organs are sensitive to hormones $(4,22)$.

Uterine prolapse associated with pregnancy is quite rare and is potentially harmful condition when not properly handled. Complications resulting from prolapse of the uterus in pregnancy vary from minor cervical edema, cervical infection to spontaneous abortion, and include preterm labor and maternal and fetal mortality as well as acute urinary retention and urinary tract infection (21). In our study, both cases were preterm labor, and we found the active prenatal treatment is necessary. Two women were given corticosteroids to promote fetal lung maturation. All newborns had no abnormality and showed good score, except for twins needed pediatric care because of their low weight. However, there is no standard guideline on the management of this condition. A vaginal pessary and bed rest may be helpful to avoid complications during pregnancy $(16,19,20)$. Careful assessment and individualized treatment seem to be essential to prevent complications during delivery, although the treatment options are very limited.

Acute edema of the prolapsed cervix both have been seen in our two patients. Cervical edema due to venous obstruction may be the first major symptom of uterine prolapse. The literatures suggested that maintaining conservative treatment in pregnancy can result in uneventful, normal, spontaneous delivery (2). Uterine prolapse during pregnancy should be managed conservatively. Unfortunately, there was no opportunity to make attempt of vaginal delivery in our current study, although the second patient expected to vaginal delivery in her early pregnancy. Two patients all treated with conservative management, and followed by emergency cesarean section without complicated and eventful outcomes. The patients with cesarean section did not because of acute edema and dystocia in labor but 


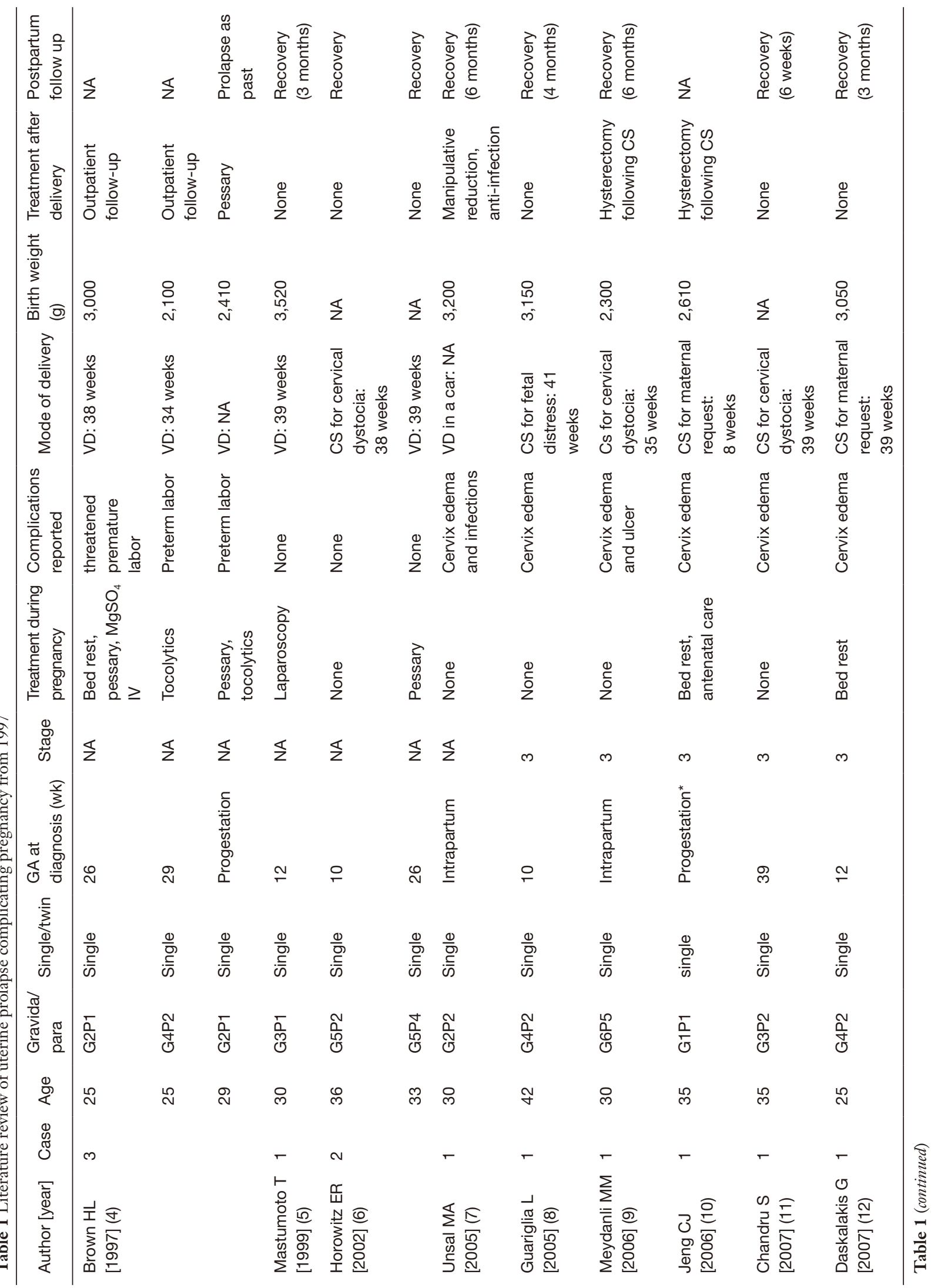




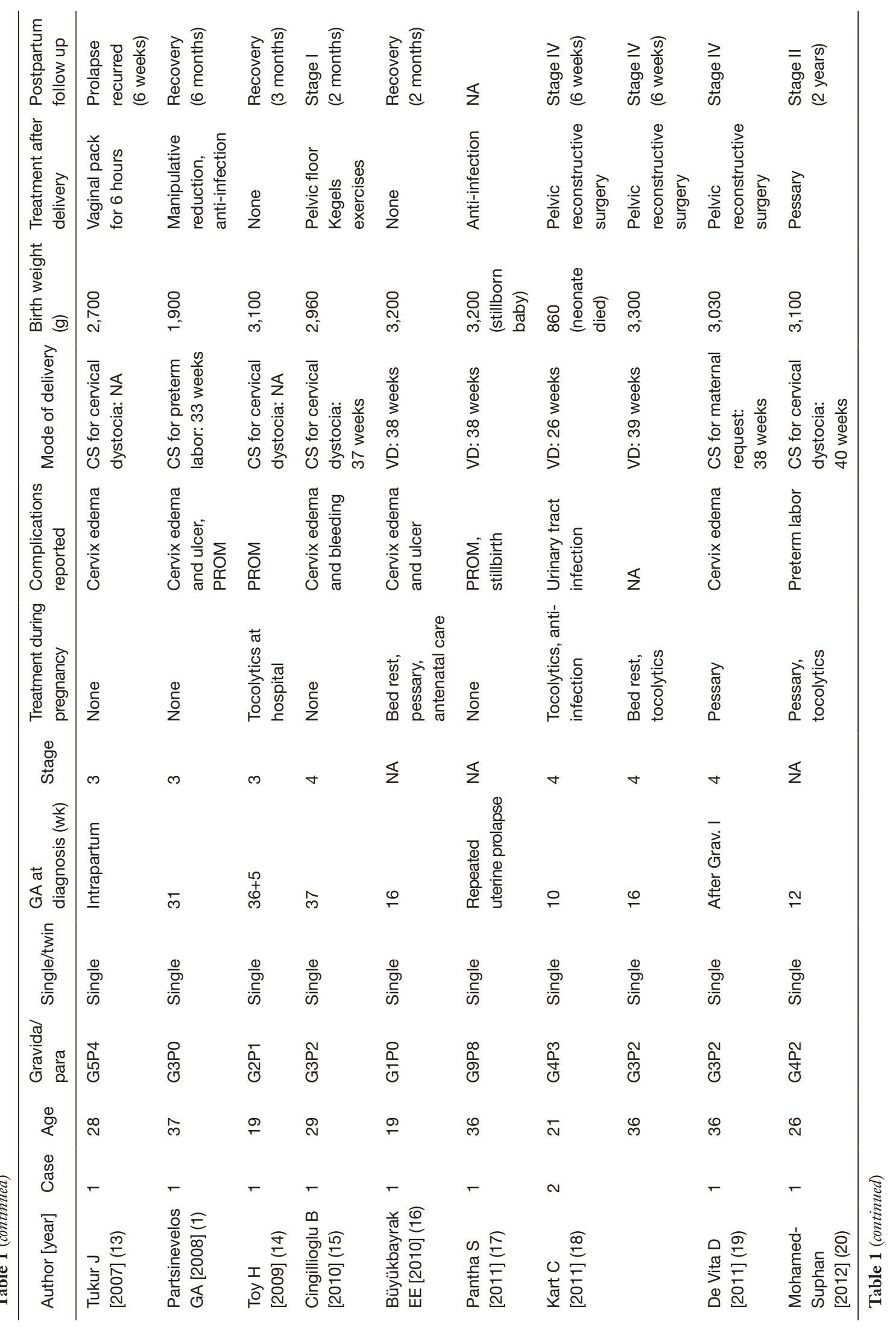




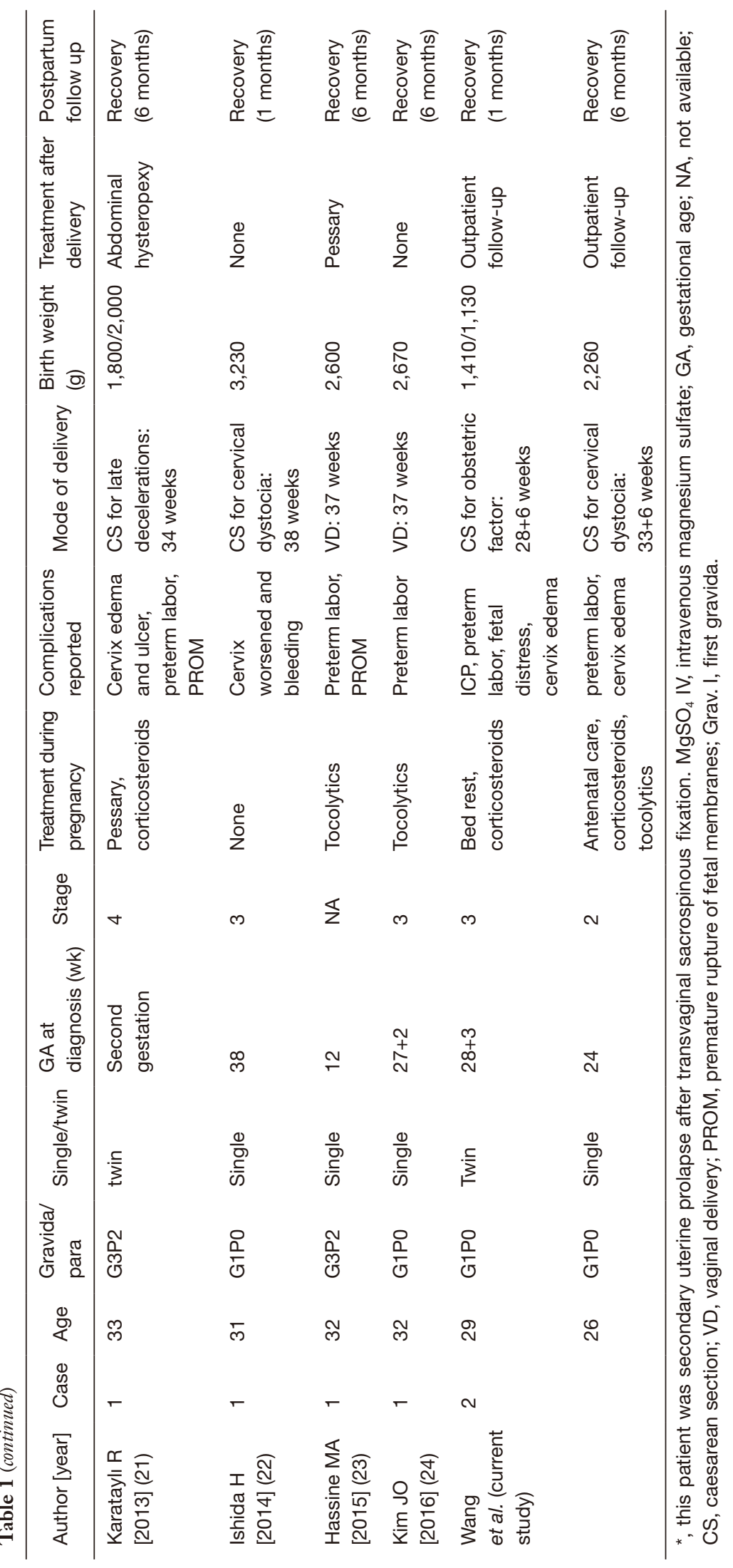



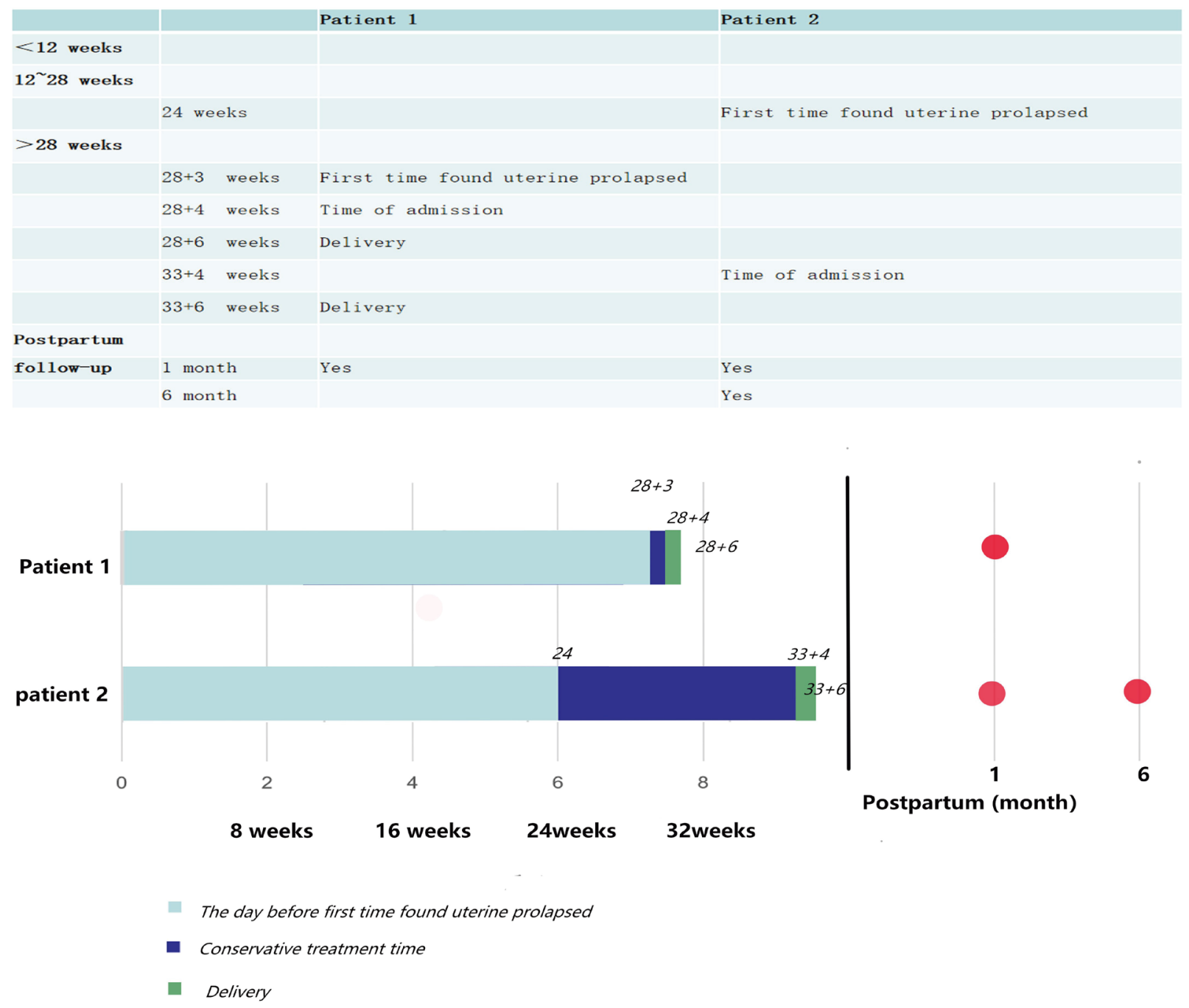

Figure 2 The timeline of two cases. The timeline consisted of two parts, one is parturition stage, which including the time of first found uterine prolapsed, the time of admission and delivery; another is postpartum follow-up.

because fetal distress and vaginal bleeding. The acute and progressive cervical edema in labor may lead to dystocia, uterine rupture, and may associated with possible maternal and fetal risks. If vaginal delivery was impossible, elective caesarean section should be a better alternative.

According to previous literature reports, pregnancy with uterine prolapse often occurred in late pregnancy or during delivery. Of the 26 previously reported patients, 10 patients occurred in the third trimester of pregnancy (stage 3) and 5 occurred during delivery (stage 4), but no one was found in the second trimester of pregnancy (Table 1). In theory, if the uterine prolapse occurs more earlier, the complications during pregnancy and adverse outcomes was more serious, the probability of premature birth was greater. But in our report, the second case was found uterine prolapse at 24 weeks of gestation. This women was given effective prenatal care and treatment, she had fewer pregnancy complications than the first one, and the gestational age of delivery was higher (Figure 2). Therefore, these results suggested that the prognosis of uterine prolapse during pregnancy may not be positively correlated with the gestational age. What's more important is to find out the problem early and give active and effective treatment and prenatal care that can reduce the incidence of pregnancy complications. 
In conclusion, we suggested that the successful pregnancy outcome of uterine prolapse depending on symptomatology, severity of the prolapse, obstructed status and the preference of patients; based on these facts require individualized management and treatment. When the risk factors relieved after the delivery, the uterine prolapse may recover spontaneously under careful post-partum management.

\section{Acknowledgments}

This study was approved by the Institutional Review Board of West China Second University Hospital. We feel grateful for the doctors and staff who have been involved in this work.

Funding: This study was supported by the Natural Science Foundation of China (Project No. 81571446), the Science Foundation of Sichuan Province (2018FZ0041).

\section{Footnote}

Reporting Checklist: The authors have completed the CARE reporting checklist. Available at http://dx.doi.org/10.21037/ apm-20-1322

Peer Review File: Available at http://dx.doi.org/10.21037/ apm-20-1322

Conflicts of Interest: All authors have completed the ICMJE uniform disclosure form (available at http://dx.doi. org/10.21037/apm-20-1322). The authors have no conflicts of interest to declare.

Ethical Statement: The authors are accountable for all aspects of the work in ensuring that questions related to the accuracy or integrity of any part of the work are appropriately investigated and resolved. All procedures performed in studies involving human participants were in accordance with the ethical standards of the institutional and/or national research committee(s) and with the Helsinki Declaration (as revised in 2013). Written informed consent was obtained from the patient.

Open Access Statement: This is an Open Access article distributed in accordance with the Creative Commons Attribution-NonCommercial-NoDerivs 4.0 International License (CC BY-NC-ND 4.0), which permits the noncommercial replication and distribution of the article with the strict proviso that no changes or edits are made and the original work is properly cited (including links to both the formal publication through the relevant DOI and the license). See: https://creativecommons.org/licenses/by-nc-nd/4.0/.

\section{References}

1. Partsinevelos GA, Mesogitis S, Papantoniou N, et al. Uterine prolapse in pregnancy: a rare condition an obstetrician should be familiar with. Fetal Diagn Ther 2008;24:296-8.

2. Tsikouras P, Dafopoulos A, Vrachnis N, et al. Uterine prolapse in pregnancy: risk factors, complications and management. J Matern Fetal Neonatal Med 2014;27:297-302.

3. Erata YE, Kilic B, Güçlü S, et al. Risk factors for pelvic surgery. Arch Gynecol Obstet 2002;267:14-8.

4. Brown HL. Cervical prolapse complicating pregnancy. J Natl Med Assoc 1997;89:346-8.

5. Matsumoto T, Nishi M, Yokota M, et al. Laparoscopic treatment of uterine prolapse during pregnancy. Obstet Gynecol 1999;93:849.

6. Horowitz ER, Yogev Y, Hod M, et al. Prolapse and elongation of the cervix during pregnancy. Int J Gynaecol Obstet 2002;77:147-8.

7. Unsal MA, Zengin U, Ozeren M, et al. Uterine prolapse immediately after labor. Saudi Med J 2005;26:150-1.

8. Guariglia L, Carducci B, Botta A, et al. Uterine prolapse in pregnancy. Gynecol Obstet Invest 2005;60:192-4.

9. Meydanli MM, Ustün Y, Yalcin OT. Pelvic organ prolapse complicating third trimester pregnancy. A case report. Gynecol Obstet Invest 2006;61:133-4.

10. Jeng CJ, Lou CN, Lee FK, et al. Successful pregnancy in a patient with initially procidentia uteri. Acta Obstet Gynecol Scand 2006;85:501-2.

11. Chandru S, Srinivasan J, Roberts AD. Acute uterine cervical prolapse in pregnancy. J Obstet Gynaecol 2007;27:423-4.

12. Daskalakis G, Lymberopoulos E, Anastasakis E, et al. Uterine prolapse complicating pregnancy. Arch Gynecol Obstet 2007;276:391-2.

13. Tukur J, Omale AO, Abdullahi H, et al. Uterine prolapse following fundal pressure in the first stage of labour: a case report. Ann Afr Med 2007;6:194-6.

14. Toy H, Camuzcuoğlu H, Aydın H. Uterine prolapse in a 19 year old pregnant woman: a case report. J Turk Ger Gynecol Assoc 2009;10:184-5.

15. Cingillioglu B, Kulhan M, Yildirim Y. Extensive uterine 
prolapse during active labor: a case report. Int Urogynecol J 2010;21:1433-4.

16. Büyükbayrak EE, Yılmazer G, Ozyapı AG, et al. Successful management of uterine prolapse during pregnancy with vaginal pessary: a case report. J Turk Ger Gynecol Assoc 2010;11:105-6.

17. Pantha $S$. Repeated pregnancy in a woman with uterine prolapse from a rural area in Nepal. Reprod Health Matters 2011;19:129-32.

18. Kart C, Aran T, Guven S. Stage IV C prolapse in pregnancy. Int J Gynaecol Obstet 2011;112:142-3.

19. De Vita D, Giordano S. Two successful natural pregnancies in a patient with severe uterine prolapse: A case report. J Med Case Rep 2011;5:459.

Cite this article as: Wang $\mathrm{K}$, Zhang J, Xu T, Yu H, Wang X. Successful deliveries of uterine prolapse in two primigravid women after obstetric management and perinatal care: case reports and literature review. Ann Palliat Med 2021;10(6):70197027. doi: 10.21037/apm-20-1322
20. Mohamed-Suphan N, Ng RK. Uterine prolapse complicating pregnancy and labor: a case report and literature review. Int Urogynecol J 2012;23:647-50.

21. Karataylı R, Gezginç K, Kantarcı AH, et al. Successful treatment of uterine prolapse by abdominal hysteropexy performed during cesarean section. Arch Gynecol Obstet 2013;287:319-22.

22. Ishida H, Takahashi K, Kurachi H. Uterine prolapse during late pregnancy in a nulliparous woman. Int Urogynecol J 2014;25:1739-40.

23. Hassine MA, Siala H. Uterine prolapse in pregnancy. Pan Afr Med J 2015;22:188.

24. Kim JO, Jang SA, Lee JY, et al. Uterine prolapse in a primigravid woman. Obstet Gynecol Sci 2016;59:241-4. 